\title{
A PSYCHIATRIC VIEW OF GYNAECOLOGY AND OBSTETRICS
}

\author{
By Desmond O'Neill, M.D., M.R.C.P., D.P.M. \\ Department of Psychological Medicine, Guy's Hospital
}

The view which will be put forward here may be stated briefly thus:- That the part-functions of the human organism which are the gynaecologist's field of study depend for their smooth working, to a considerable degree, on the success or failure of the organism in the larger function of living; that reverses in the struggle of life are often reflected in the malfunctioning of the processes of menstruation and reproduction. This view, in its essence, is as old as medicine itself. The last two or three decades, however, have witnessed a remarkable revival of interest in the concept of illness which is contained in it, and to which the term 'psychosomatic' is sometimes applied. The interest has shown itself in a steadily rising tide of contributions to medical literature from clinicians and experimental workers who are concerned to explore and elucidate the psychophysical relationships in every branch of medicine. It shows itself also in the increasing emphasis given by the clinician to the emotional elements in the disorders which make up his day-to-day practice. Many competent practitioners have estimated the proportion in general practice of psychosomatic disorders, employing this term in its widest sense, at onethird or one-half of the total; some, working in metropolitan areas, have considered it to be even higher. Until an adequate morbidity survey has been made, it is impossible to assign a proper value to these observations. It may be that the presentday clinician is more aware of this aspect of his work, or there may be an absolute increase in the 'stress disorders' from the discontents and apprehensions of our time-a new epidemic, to replace the infective illnesses of bygone days. Women are not less subject to these disorders than men; in fact, since they have during the late war arrogated to themselves several masculine functions and demanded equality of status, they may be expected to acquire some of man's diseases as well as some of his rights.

No attempt will here be made to account for the ;occurrence of any disorder solely in psychogenetic terms. It is taken as an axiom that every illness has a multiple aetiology. Mind enters to a greater or lesser extent into all behaviour, including the aberrant behaviour of disease, but in many conditions the psychic factor is not significant. Every formulation of aetiology must comprehend the causal factors in their due proportion. A study of women with overt homosexual tendencies has shown certain somatic peculiarities, such as hirsuties, contracted pelvis, and small breasts, which may be regarded as part of a constitutional endowment (Henry, 1934); in such women the abnormal sexual direction may perhaps owe less to environmental circumstances and more to innate predisposition. Success in adaptation to life may be impaired by bodily malformation and disease, by mental instability and ineptitude, by experiences which warp and hinder normal development. The influence of such injurious experiences is not uniform; some people appear to weather violent emotional storms in early life without illeffect, while others are hurt and handiçapped. Failure and frustration, from whatever cause, react on the organism as a whole. The emotions to which they give rise may be expressed in outward behaviour or in internal dysfunction; one large area of psychosomatic research is devoted to dysfunction of this kind, its form and localizationg $A$ vast number of experimental and clinica observations bearing on this subject have beew recorded; some of these, which are relevant to our present theme, have been summarized by Wolff (1947); the vascular supply to the mucosa of the stomach and nose has been shown to alter with the emotional state of the subject, and analogous changes are known to occur in the bladder, vagina and large bowel. The psychosomatic concept of some conditions has been put to the test by treatment which makes use of the knowledge gained by investigation of the body and mind together; as will be mentioned later, in some cases of menorrhagia such treatment has been quickly effective.

The criticism is sometimes made that attempts at research into the psychiatric aspects of medicine tend to be speculative and impractical, and to lack objectivity. This criticism is no doubt occasionally justified; as with any new approach to old problems, the first wave of enthusiasm threw up some formulations which showed more enthusiasm than sense. However, nothing could be less speculative than the experimental findings noted above; Wolff's own study of the behaviour of the stomach in emotional states (1943) is a classic in applied physiology.

Bryson (I945) reported that of a total of 4,000 women seen in gynaecological practice 2,500 required some psychological understanding for their proper management; she remarks that if help had not been available in this way, very many women 
could not have been helped at all. Snaith (1948) has described the establishment of a psychiatric clinic within the gynaecological service of a general hospital, for the purpose of assessing the degree to which somatic symptoms in each patient were influenced by psychological factors, and giving such short-term psychotherapy as was practicable. Personality, heredity and constitution, and personal history were studied in each case. The major aetiological factors were found to be:Maladjustment to the husband, fear of pregnancy and emotional immaturity. Inability to adapt to marriage was found to be associated with earlier faulty relations with one or both parents; maladjustments between patients and their children seemed in all cases to be secondary to maladjustment to the husband or to the patient's own mother.

\section{Menstruation}

The onset of menstruation is an event of profound psychological significance, which arouses echoes from the early experiences of the individual and of the race. 'In the modern and the ancient world, among the most primitive as well as the most civilized peoples, menstruation was, and still is, connected with ideas of horror, danger, shame and sin' (Deutsch, 1947). The taboos of the primitive and the superstition and prejudice which surround menstruation in the present day are closely linked. Magical powers of causing harmof blighting crops, of turning wine to vinegarwere attributed to the menstruating women by Pliny; in modern society, the shadows of these old beliefs can still be seen; an example is the fear of cohabitation with a woman during the period.

The girl's attitude to menstruation derives in part from what she has learned of it from her parents; this is itself a function of their attitudes to sexual matters in general. It is still by no means rare for a girl to reach the menarche without even a word of guidance from her mother; many women cannot bring themselves to speak to their children of sex, because of the anxiety and guilt which any mention of it stirs up in their own minds. The way in which sex instruction is regarded, in each community, depends on its social structure; there is considerable variation in outlook even within the British Isles. Helene Deutsch believes that the reaction to menstruation is to some extent independent of intellectual knowledge of it. Apparent ignorance may be the result of repression of an early and strong sexual curiosity; indifference to or denial of sexual interest is one form of defence against a welling-up of libidinal urges. The association of menstruation with feelings of inferiority, guilt and 'dirtiness' owes something to the relation between menstrual bleeding and excretory functions.
A feeling of resentment against menstruation is often found in association with dysmenorrhoea; the resentment may precede the pain (Wittkower, 1940). The notion of the menstrual period as a time of illness is demonstrated by the popular euphemism ' unwell.' Both mental and physical symptoms are. in fact common at this time. In a series of college students and professional women, backache was reported in 40 per cent., and increased fatigue in 63 per cent.; depression in 49 per cent., and irritability in 59 per cent. (Brush, 1938). In an extensive study by McCance (1937) of physical and emotional periodicity in women, only io per cent. of the subjects studied were able to record that they had no pain at all; a greater or lesser degree of fatigue was recorded by the majority on at least one day of the cycle. A general relationship between mood and menstrual function among patients with mental disorders was described by Allen (1935). A depressive mood and motor underactivity were found to be associated with amenorrhoea; an expansive or elated mood, and motor overactivity, predisposed to a profuse and prolonged period. Agitation and worry were more apt to accompany a profuse than a decreased flow.

The degree of disturbance which the period causes may often be shown to vary from one stage of the patient's life history to another; it is sometimes much intensified when there is emotional tension. When the woman is already in grave conflict over a sexual theme the period may precipitate a reaction so acute as to merit the term psychosis.

A woman of 35 was referred because of attacks of irritability and depression occurring at the time of the period. The attacks had been present for five years but had recently become so severe that her husband said that while they were going on he felt afraid to leave her. Before the marriage the husband was discovered to have tuberculous disease of the testes; an operation was advised but he refused to give his consent to it unless his fiancée promised to marry him. She gave this promise in the knowledge that after the operation the man might be sterile, but fearing that if she did not he might die of general tuberculosis. Throughout the marriage her husband was quite impotent and no coitus took place. The patient grew increasingly embittered; she had always wanted a family and though one child was adopted she felt that her life was empty and unfulfilled. In the attacks which accompanied each period she was openly hostile to her husband and the adopted child, and spoke of suicide. One attack was witnessed while she was under observation in hospital. The patient was withdrawn, tense, depressed and suspicious. She reiterated her desire 
to kill herself and said that as soon as she could get out of hospital she would jump over London Bridge. There was no doubt that this intention had to be taken seriously. After the end of the period she relaxed a little, became more accessible and was ready to admit that her attitude was unreasonable and that other solutions to her difficulty might be considered.

The general conclusion which McCance and his collaborators drew from their study was that many physical symptoms and emotional trends in women showed a clearly marked rhythmical variation in each menstrual cycle. There was, for example, a regular variation in irritability, with a considerable increase in the pre-menstrual phase and a sharp fall between the first and fifth day of the cycle. The amount of effort required for intellectual work similarly varied; the effort was least on the twentieth day of the cycle, rose to a peak on the first day and declined to the fifth day. The incidence of complaints of fatigue, as reported by the women themselves, was three times as great on the first and second days as on the twentieth. The main peak of sex feeling was on the eighth day. That many women tend to feel depressed in the premenstrual phase of the cycle has often been observed in clinical practice. A depressive mood was shown to occur during this phase in 60 per cent. of the college students investigated by Altmann (194I). A high incidence (72 per cent.) of bursts of physical and mental activity-' premenstrual tension'-was reported in this series. In most cases this 'tension activity' was accompanied by a critical attitude towards other people and gave rise to conflicts. Altmann found that the mood disturbance could be related also to the pressure of academic work. He did not consider that fatigue was wholly due to the hormonal changes of the cycle, since it occurred mostly after long hours of work or play.

Benedek, in 1939, published the results of an ingenious experiment which had the aim of discovering a correlation between ovarian activity on the one hand, and mental attitude and content on the other. The former was followed by a day-today study of vaginal smears and body temperature: the latter by an application of the psychoanalytic method-analysis of free associations, dreams and fantasies. It was found that in the adult woman heterosexual interest could be correlated with oestrone activity and a passive, receptive, narcissistic' attitude with progesterone activity. When an active heterosexual drive, either as sexual desire or a defence against it, appeared in the patient's thoughts, oestrone was being produced in sufficient amount for its effects to be apparent in the vaginal smear. When progesterone activity was recognizable, the patient's attitude changed; her thoughts became more concerned with her own body, and receptive and dependent behaviour came into prominence. In dreams and fantasies the oestrone phase was represented by a wish for, or fear of, sexual gratification, and the progesterone phase by the wish to be impregnated and to have a child. These findings are concerned with the spontaneous mental changes associated with the hormonal cycle; of course, for each individual woman the form of expression is moulded and modified by her life situation.

It is common knowledge that a disturbing experience may be followed by amenorrhoea. Illicit intercourse, which sets up the fear of an unwanted pregnancy, is in practice a very frequent cause. The results of an endometrial biopsy on four women who had missed a period after an emotional shock were reported by Loeser in 1943. The biopsy showed an endometrium at the stage it would normally have reached at the time of the shock, suggesting that the shock caused an immediate arrest of development by interruption of hormone release. The mechanism of this arrest may be the action of the autonomic nervous system on release of gonadotrophic hormone. The contributory causes of a psychogenic amenorrhoea may be manifest or they may not come to light without a special enquiry.

A girl of 21 was referred because of amenor rhoea. She had been thoroughly investigatect from the physical standpoint and nothing had been found which could account for the amenorrhoea. She said that her home life was happy, that she was engaged to be married and was looking forward to the wedding, yet she felt weak, listless and sleepy, and was plainly depressed. It was noted by one of the Ward staff that when her fiance came to visit her he and she sat in complete silence. Her mother was interviewed; she was a rubicund, jovial, dominating and possessive person who said that her daughter had always been rather backward, 'childish in her mind,' and greatly attached to her home. She said that she thought the girl was really unfit to marry and was unable to manage a home, and that she had recently taken to insulting her fiance. After further investigation it became clear that the condition could be considered a depressive state which was a reaction to the prospect of leaving home; the patient was very dependent on her mother and much under her influence, and could not contemplate a separate existence. The amenorrhoea was one of the physical concomitants of this state.

The intensity of pain felt during the period and the degree of distress which it occasions depend on the patient's general health and her mental wellbeing. A tendency to dysmenorrhoea is one element of the 'Atalanta syndrome.' An ' attack' 
of dysmenorrhoea may be coincident with a physical illness or with a sustained emotional tension.

A married woman of $3 i$ was referred because of dysmenorrhoea, intermenstrual bleeding, pain in the back and indigestion. Menstruation began at 14 and there had always been pain at the periods. She married at 27 and gave birth at 28 . As they had nowhere else to live she and her husband stayed with her husband's parents after the birth. Her husband was an only child; his parents did not approve of the marriage and the patient felt that their attitude was selfish and inconsiderate. During her stay with them the dysmenorrhoea became more marked and the periods more profuse. The dissatisfaction with her parents-in-law blew up into a ' real fight,' and she and her husband left the house to live elsewhere. The child died at nine months from pink disease; the patient considered that the medical attention given to it had been inadequate and that the condition had been overlooked. She felt miserable, disappointed and resentful; the pain which accompanied the period grew still more severe.

Wrigley (1949) considers that when the few certain causes of menstrual pain, such as inflammation, can be excluded, no generally acceptable explanation in physical terms can be put forward for the remainder. Physical investigations, important as they are, can be pursued too far. There is a risk that the physician's attention and the patient's interest may become too much concentrated on the pelvic organs, and that the former may tend to lose sight of his patient as a person with her own immediate hopes, desires and fears. With the exception of castration and presacral neurectomy, all methods or treatment of dysmenorrhoea appear to give about the same proportion of successful results (Hunter, 1947); it is likely that suggestion enters into the treatment of most cases. Where dysmenorrhoea can be related to a tension state it is likely to be relieved when this state is cleared up by appropriate treatment.

Wittkower examined a group of patients with primary dysmenorrhoea in 1940. He found that they could be divided into two main classes. In the first, the women showed some masculine characteristics in their manner and bearing, and in their ambitions and tastes. They could be said to manifest resentment of the female role in life; for them the period was a nuisance and a handicap which they found hard to accept. The second group tended to be small and lightly built; in personality they were either timid, seclusive and shy or hypochondriacal and self-concerned. The outstanding feature of this group as a whole was a physical and emotional immaturity.
A girl of 17 was referred because of acne urticatus and dysmenorrhoea. The periods began at 13 and with each period she would vomit. The vomiting ceased while she was on holiday and began again when she went back to school. She started to have severe pain at the period, and while menstruating felt ill and weak and had pins and needles in the limbs. The rash first appeared at the same time as the pain. The girl had been a form captain throughout her school life and was now a prefect; she took responsibility well and could ' manage people.' She described herself as ' more grown-up than others.' She preferred boys' company to that of girls, and played hockey for the school team. Her ideal state was to be independent. She said that she would rather have been a boy and often wished ' the periods weren't there.' She was interviewed several times, and her attitudes towards menstruation and towards her own function in life were fully discussed. One year later the mother wrote to say that the skin had cleared, that the periods were much less troublesome and the girl was well and happy.

Blaikley (1949) reports nine cases of psychogenic menorrhagia. In each of these the bleeding could be shown to have followed directly on experiences" which had been emotionally disturbing to the patient. Three of the women had been subjected to perverse sexual demands by their husbands. Sexual maladjustment was, however, only one of a variety of contributory causes. One patient in the series was $5^{8}$ at the time of examination. All three of her sons had been killed in the R.A.F., and it was found that the bleeding, in every instance, occurred on the birthday or day of death of one of the sons. In seven of the nine patients, simple psychotherapeutic measures put an end to the menorrhagia. Blaikley holds that psychogenic menorrhagia is much commoner than is generally believed. The importance of its recognition is obvious; in the first place the condition usually responds readily to psychotherapy. Increased length of the period, increased flow and a shortened cycle are all fairly common; intermenstrual bleeding may also be regarded as psychogenic in some cases. Fremont-Smith (1948) has described the investigation and treatment of a woman of 26 who had had profuse and irregular periods since the onset of menstruation. The disorder was shown to be psychogenic, and after psychotherapy the periods became normal. Thus even when there is a history of menstrual dysfunction extending back to the menarche, the possibility of an emotional origin for excessive bleeding cannot be excluded. The mechanism of the bleeding is not clear. Wolff (1947) has stated that the mucosae of the stomach, nose, bladder, large bowel and vagina show changes in vascu- 
larity with emotion, and it may be that such changes are common to all mucosae. Uterine bleeding may be due to hyperaemia of the endometrium.

Psychogenic menorrhagia is as a rule accompanied by other symptoms, such as tension, irritability, headache, giddiness and poor sleep. The diagnosis is reached by a consideration of the. patient's personality, her situation and how she is reacting to it.

A woman of 23 was referred because of heavy periods occurring at intervals of two weeks. Some months before her sister had drowned herself and the patient had been asked to identify the body. On the day of the suicide the sister had been preparing to go out when the patient's child made a dirty mark on her skirt; she flew into a temper, there were ' words' and she then went up to her room and cried. This was the last time the patient saw her alive. It was clear that the patient had considerable guilt about the suicide, and felt that had she not quarrelled with her sister it might never have happened. The period which was due at this time did not appear; at the next period she began to have flooding. On one occasion, between two periods, she went to visit a friend of her sister. She knew that the friend would enquire about her sister's death; a short time before she set off bleeding began. After discussion of the relation between herself and her sister, when her guilt feelings had been to some extent alleviated, the periods decreased in length, the flow diminished and the interval returned to normal.

\section{Reproduction}

The reproductive functions are close to the core of woman's personality; for this reason they are the more readily disturbed by psychic disharmony and tension. A comprehensive survey of the psychological aspects of these functions and their disorders is given by Helene Deutsch (1947); in the second volume of her study of the psychology of women she shows clearly how the mind can influence the performance of the sexual act, conception, pregnancy, delivery and lactation. Emotional fartors in pregnancy are discussed by Menninger (1943); he points out that many conscious reasons are put forward for the avoidance of pregnancy, but some of these are rationalizations. Many apparently well-adjusted women have no wish to bear children and may show aversion to becoming pregnant; in them there is and unconscious repudiation of the female role and perhaps an 'identification' with a masculine figure. There are many neurotic reasons also for wishing to be pregnant, as a weapon to accomplish other ends, as an escape, as a hold on the husband, as a means of ensuring support. A pregnancy which is unwanted is less likely to run a smooth $\frac{3}{8}$ course than one which is planned. Transient $\stackrel{\mathbb{Q}}{\unrhd}$ signs of denial or rejection of the pregnancy are $C$. to be seen in most women; irritability, a critical $\Rightarrow$ or exacting attitude, self-depreciation. Vomiting $\stackrel{0}{?}$ in pregnancy is in some women a psychogenic $\frac{C}{0}$ symptom.

A woman of 39 brought her child for examina- $\frac{D}{D}$ tion because of vomiting. There were four $\cong$ members of the family and all four had psycho- $\%$ somatic disorders. The husband was irritable and $\vec{\circ}$ sometimes violent, and suffered from severe headaches; the other child had enuresis and $\vec{\omega}$ screaming attacks, and was obsessively tidy. The $\frac{\Omega}{0}$ patient herself was of square build with-broad $\frac{0}{3}$ shoulders, the breasts were small and there was hair on the chest and upper lip. She gave a $\overparen{N}$ history of three ' nervous breakdowns.' Since the if menarche she had felt pain at the period and $N$ sometimes fainted. There had been one miscarriage. She cared little for intercourse: 'I 의 hate it really, I feel it's a duty.' In each pregnancy she vomited continuously and suffered a great $T$ deal. She 'married to get away from home,' ' hated domestic life and always wanted to be a business woman.' She held a secretarial post $₹$ until her marriage and as soon as both childrem $\overrightarrow{0}$ were at school went back to it. She was a con o scientious and diligent person who did a full days work at the office yet was able to look after her family well and keep the house scrupulously clean.

The psychogenesis of frigidity is outlined by Knight (1943). He considers that a large pro-

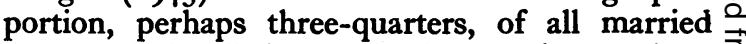
women derive little or no pleasure from coitus, many actually suffer pain and revulsion. Many remain ignorant of the existence of orgasm, many simulate orgasm. These women may consult the gynaecologist about other things but their real disorder is frigidity. Frigidity and dyspareunia are not clinical entities but symptoms of dis- 3 . turbance of psychosexual development. The female sex is hedged about much more than is the male with restrictions and warnings, anxieties 0 about menstruation, intercourse, childbirth and the menopause are transmitted from the old to the $\frac{D}{0}$ young. Some of the main psychological mechanisms of frigidity are described, guilt over $\mathcal{N}$ sexual activities which is a legacy of childhood, $N$ unconscious resentment of men springing from $N$ envy of masculine attributes, conflicting loves, the $\sigma$ desire for individual achievement outside marriage (the ' career girl'), total absorption in domestic $\frac{0}{\varnothing}$ duties (the 'house proud'). Kroger (1946) re- $\stackrel{\oplus}{\rightarrow}$ ports the results of treatment of frigidity by 0 hypoanalysis; nine out of 12 patients were per- $\overline{0}$ manently relieved of the symptom by this method. $\stackrel{\mathbb{8}}{\circ}$ Frigidity and distaste for coitus are found in the 
'Atalanta syndrome.' Difficulties in, sexual , relations may sometimes be a sequel to injurious experiences in early life.

A married woman of 20 was referred because of complete incapacity for coitus. This took the form of extreme tension when intercourse was attempted; the husband stated that 'the passage seemed blocked.' When the patient was I4 her father had one day kissed her ' in an unpleasant way,' and had later exposed himself to her. This aroused in her an acute fear that he might assault her and a feeling of disgust and disappointment that her father should so degrade himself. When her husband attempted intercourse the memory of this incident rose up in her mind and she became agitated and fearful. Over the nine months of married life, although many attempts at intercourse had been made, no penetration had ever occurred.

Helene Deutsch (1947) recognizes five main forms of psychogenic sterility. The first is found in the woman who is physically and physiologically infantile, small, dainty, dependent and usually vaginally frigid. She insatiably demands proofs of tenderness, and her own tenderness is that of a child not a mother. If she conceives it may be after a long delay; she may transfer her psychic difficulties to the later phase of the reproductive function. The second type is found in the motherly woman married to an unfatherly man, who does not need or want children. The woman senses that the harmony of the marriage would be threatened by pregnancy and unconsciously avoids it. The third type is_represented by the woman who devotes her life to an ideology or an emotionally determined interest; here belong those women who play a part in revolutionary movements, the artists and the scientists. The fourth type is found in the masculine-aggressive woman who refuses to accept femininity, and the fifth in the emotionally disturbed woman who fears additional burdens and remains sterile because she perceives the poverty of her own emotional life. I have found that relative sterility, in the sense of delay in conceiving, in the absence of contraceptive measures, is not infrequently associated with dysmenorrhoea and hyperemesis during pregnancy. In the sterile woman the wish to avoid pregnancy may be masked by a demonstrative eagerness for a child.

A married woman of 29 was referred because of multiple somatic symptoms; a burning sensation in the leg, palpitation, pain in the face and chest and frequency. She married at 20 and gave birth a year later. Since then she had 'never been well.' She ' wanted another child badly,' 'envied people who have children.' She felt bitter that other women had children ' who didn't want them.' If she heard that a friend had given birth she became depressed and wept. She had employed no contraceptives and had tried to conceive for six years, but without success, although a gynaecologist had found both Fallopian tubes to be patent. At successive interviews it became clear that she believed herself to be sterile, that she thought one child was quite enough to manage, that her conscious wish for more children was purely competitive, and that she did not wish to co-operate in exploration of the psychological basis of her sterility. Finally she refused to continue attending hospital.

Four features have been reported which are common to many women who show the pattern of abortion, premature delivery and stillbirth, these are:-Identification with the father, frustration in a career, frigidity and concern about the sex of the baby (Squier, 1946). Some patients may develop an abortion habit as others develop an accident habit, this may respond to psychiatric treatment. Women with the "Atàlanta syndrome' often report one or several 'misses' during their obstetric history, in many of them this tendency is accompanied by a distaste for sex relations. A feeling of distaste or even disgust for coitus has been described as a concomitant of nausea and vomiting in pregnancy (Robertson, 1946). The symptoms of abdominal distension, belching, regurgitation of gastric juice and later nausea in frigid married women are related to this disgust and are, in a sense, its somatic expression. Of 100 pregnant women examined by Robertson, 57 had nausea and vomiting. Of these 40 had disturbance of sexual function, such disturbance was found only four times in the other 43 .

The intensity of pain in childbirth has been estimated in a series of women in labour by dolorimetry (Hardy, 1949). The unit of pain was the 'dol,' this represents one-tenth of the interval between threshold and ceiling pain. During the first stage of labour pain rose from threshold level to 5 dols at the mid-point and ro dols at the end. In the second stage pain remained at the ceiling level and in the fourth it fell from 3 to 5 dols to threshold level in about two hours. The intensity of pain in the first stage was roughly proportional to the extent of cervical dilatation and inversely proportional to the duration of the interval between uterine contractions, the most intense pain of all was that due to stretching and tearing of the tissues of the perineum, with stimulation of the perineal reflex and increase of intra-uterine pressure. The reaction to labour and the degree of discomfort are bound up with the woman's attitude to it. That the discomfort can be reduced by appropriate education has been claimed by Dick Read (1949); his views on the preparation for, and the conduct of labour are 
well known. He considers that the essential disturbing factor is not the physical distress but the 'emotional menace' of labour, nervous tension may prevent full relaxation of the cervix and hinder delivery. Experimental evidence in support of the contention that much of the pain of childbirth is the result of high sympathetic tone is quoted by Woolman (I949). Atropine given to women in labour increased rigidity of the cervix and raised the tone of the corpus uteri, dihydroergotamine produced relaxation of the cervix. In practice the physiotherapist has an important role in the antenatal period in teaching the primipara what she should expect in the course of a normal labour and giving instruction in relaxation exercises.

\section{Conclusion}

Some time ago when investigating a group of children who had been referred because of a psychosomatic condition, I noticed that the mothers of these children tended to suffer from two or more of a series of gynaecological disorders. Of the series, dysmenorrhoea, irregular menstruation, distaste for sex relations or dyspareunia, delay in conception, abortion or miscarriage, vomiting in pregnancy, difficult labour, postpartum depression and failure of lactation, the majority of the mothers examined showed two, a number showed three or four and several showed six elements. It seems clear that the thread which runs through this series cannot be a purely physiological one. Bertling (1948), in a survey of I, 000 patients, found an association between dysmenorrhoea and nausea and vomiting of pregnancy much greater than that to be expected on chance alone, it is inferred that there is some link between these two dysfunctions which could be psychogenic since no anatomical or physiological link is known. A clue to the nature of this link was given by Menninger in 1939. He described the somatic effects of an unconscious repudiation of femininity in women; employing this concept he was able to bring together a group of gynaecological disorders similar to that mentioned above. This is an excellent example of the unifying value of the psychosomatic approach to medicine, the bringing together of a group of apparently unrelated states which can be understood in the light of a single central concept. It is not suggested that the factor of repudiation or denial of the female role is in itself a sufficient determinant of each or all of these disorders, they may have other determinants both psychological and physiological. It does appear, however, that the disorders tend to associate with one another and with a state of disharmony in the mental field, this association is encountered often enough to merit a designation of its own and I have tentatively named it the "Atalanta syndrome. Much more work is of course needed to define the symptom-complex and to explore the various aetiological patterns, one problem, for example, is to find the incidence of each disorder in women of ' masculine' body build.

To further the understanding of these disorders is to advance more nearly towards a method by which we can grapple with the causes of illness and not only with its symptoms. In psychogenic menorrhagia, for instance, if we can discover and deal with the sources of tension we can bring the bleeding quickly to an end; the patients are ready enough to speak of their resentments and fears if they can find someone who has the time and patience to listen. Special methods, such as narcoanalysis, are not often needed. The pathogenic forces in many instances seem to lie near the surface. It is natural to think of psychotherapy as a treatment for frigidity and dyspareunia, we are coming to think of it now as a treatment for vomiting in pregnancy, for sterility and perhaps even for recurrent abortion. Under the heading of psychotherapy we may include all the means by which the patient may be helped to meet her responsibilities and to draw satisfactions from heof life, helping a woman to find part-time work and placing her child in a day nursery is psychotherap in this sense.

Sympathy and guidance will do much to restore the balance in many ill and anxious patients, though there remains always the need to recognize conditions in which more intensive therapy is required.

\section{BIBLIOGRAPHY}

ALLEN, E. (1935), Endocrinology, 19, 255.

ALTMANN, M., KNOWLES, E., and BULL, H. (1941), Psychosom. Med., 3, 199.

BENEDEK, T., and RUBINSTEIN, B. (1939), Ibid., April and October.

BERTLING, M. (1948), Amer. F. Obst. Gyn., 56, 733

BLAIKLEY, J. ( 1949), Lancet, 2, 691.

BRUSH, A. (1938), Amer. F. Orthopsych., 8, 286.

BRYSON, E. (1945), Practitioner, 155, 378.

DEUTSCH, H. (r 947 ), 'Psychology of Women.'

FREMONT-SMITH, M., and MEIGS, J. (1948), Amer. F. Obst. Gyn., 55, 1037 .

HARDY, J, and JAVERT, C. (1940), 7 . Clin. Invest., 28, 153. HENRY, G, and GALBRAITH, H. (1934), Amer. F. Psychiatry.

HUNTER, W., and ROLF, B. (1947), Amer. F. Obst. Gyn., 53, 123. KNIGHT, R. (1943), Bull. Menn. Clin., 7, I.

KROGER, W. (I946), Amer. F. Obst. Gyn., 52, 409.

LOESER, A. (1943), Lancet, I, 518.

MCCANCE, R., LUFF, M., and WIDDOWSON, E. (1937), $\mathcal{F}$. Hyg., 37, 571 .

MENNINGGER, K. (1939), Ұ. Nerv. Ment. Dis., 89, 5 เ4.

MENNINGER, W. (1943), Bull. Menn. Clin., 7, 1 .

READ, G. D. (1949), B.M.F., I, 65 I.

ROBERTSON, G. (1946), Lancet, 2, 336.

SNAITH, L., and RIDLEY, B. (1948), B.M.F., 2, 418

SQUIER, R., and DUNBAR, F. (1946), Psychosom. Med., 8, 16 I.

WITTKOWER, E., and WILSON, A. (r940), B.M.Y., 2, 586.

WOLFF, H. (1947), Ann. Int. Med., 27, 944.

WOLFF, H., and WOLF, S. (I943), 'Human Gastric Function.'

WOOLMAN, A. (1949), B.M.F., I, 958 .

WRIGLEY, A. (1949), Lancet, 2, 447. 